in the laboratory, to a 'Weasel' tracked vehicle used for transport across the snow and ice.

Jouzel's own research is included - his sampling to a depth of 3,000 metres, of polar ice that was laid down some 500,000 years ago, is crucial to our current understanding of how Earth's atmosphere has changed during this time. By analysing the composition of tiny bubbles of air trapped in polar ice, he established a correlation between temperature and the concentration of greenhouse gases, specifically carbon dioxide and methane, during successive climatic cycles. By revealing what occurred in the past, scientists can understand how best to prevent further damage to the planet. Several conferences will be held during the exhibition to alert the public to the need to change attitudes and behaviours that contribute to global warming. "But Sarah Palin is not welcome," jokes Jouzel, referring to the climate-change scepticism of the Republican vice-presidential nominee in the US election. "She is not invited."

Colin Martin is a writer based in London, UK. e-mail:cmpubrel@aol.com

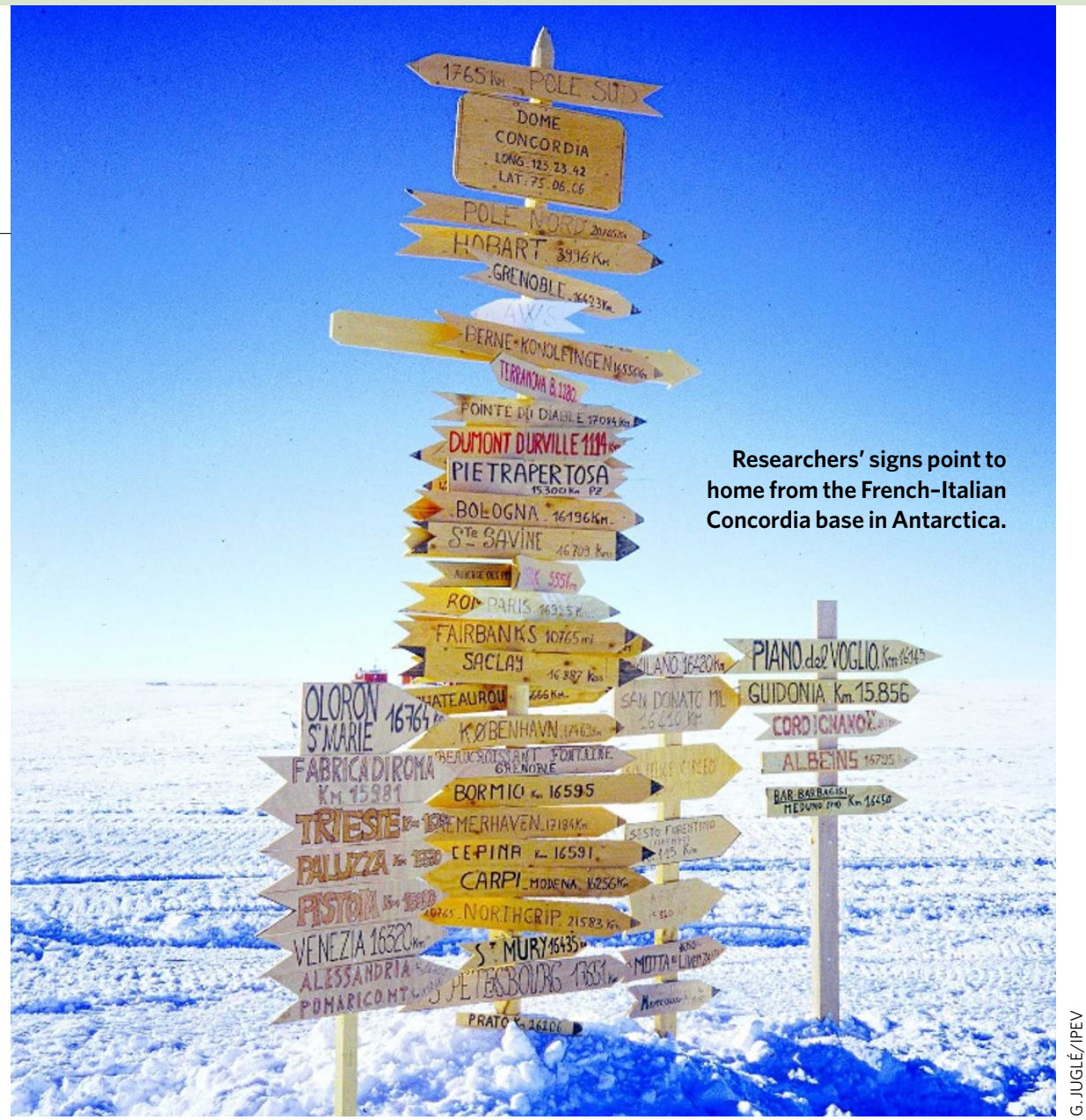

\title{
A snapshot of hidden science history
}

\section{Brought to Light: Photography and the Invisible, 1840-1900 \\ San Francisco Museum of Modern Art, California \\ Until 4 January 2009}

The use of photography in science during the nineteenth century is traced in a new exhibition at the San Francisco Museum of Modern Art, running until 4 January 2009. Brought to Light showcases scientific photographs that reveal phenomena invisible to the unaided eye, from early X-rays of the body's skeleton to fields of electricity.

Scientists first considered photography as little more than a quicker way of recording the world than drawing, but soon realized that it could be used to gain access to aspects of the world that had previously been off limits. Early photographs of the Moon, the surface of the Sun, and of distant nebulae and their spectra changed astronomers' understanding of our Universe. Popular photographs of microscopic objects, such as crystals and insects, revealed new complexity in the everyday world. Indeed, in 1877, astronomer Pierre Jules César Janssen declared that the photographic plate was the "true retina of the scientist".

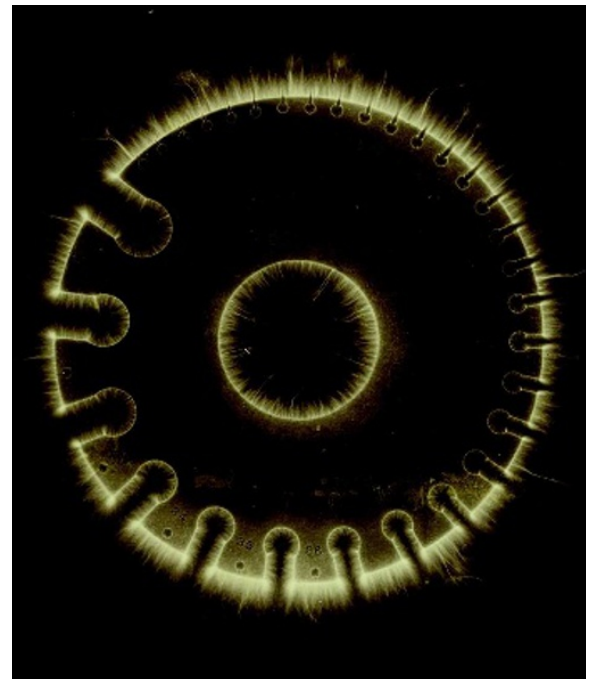

Hermann Schnauss's photo revealed how sparks of electricity emanate from a metal wire gauge.

Photography evolved rapidly with the new sciences. An X-ray image that Wilhelm Conrad Röntgen took of his wife's hand in 1895 , for instance, was widely reproduced by others who were fascinated by the ability to see inside the human body. As exhibit curator Corey Keller writes in the catalogue,
“Today we are hardly shocked by the sight of our own bones, but we can glean from the remarkable public response just how extraordinary these pictures were when they first appeared, simultaneously suggesting an assault on privacy and conjuring the specter of death."

Keller argues that, by showing there was more going on in the world than was apparent to the unaided eye, scientific photographs inspired a fundamental shift away from faith in the human observer to faith in the authority of technology. And by the end of the nineteenth century, the heyday of the 'educated amateur' had ended. Scientists were becoming the specialized practitioners they are today, using powerful, expensive and complicated tools to explore realities that remain invisible to most.

By revealing the hidden forces at work in nature, the pictures collected in this exhibit have much in common with iconic modern images, such as the views of galaxies in the distant Universe captured by the Hubble Space Telescope. In that way, the exhibit does not just illuminate the past - it also gives a glimpse of the future.

Erika Check Hayden is a correspondent for Nature based in San Francisco. 